\title{
Evaluation of Grain Density on the Surface of a Solidified Shell
}

\author{
Hisao ESAKA, Kei SHINOZUKA and Manabu TAMURA \\ National Defense Academy, Department of Materials Science and Engineering, 1-10-20 Hashirimizu, Yokosuka $239-8686$ \\ Japan.
}

(Received on April 1, 2003; accepted in final form on June 18, 2003)

\begin{abstract}
Refinement of the solidified structure is of importance for soundness of cast products. Formation of the grains on the surface is very important for the understanding of evolution of solidified structure. The evaluation method for grain density on the chill plate is proposed in this study.

Using an engineering model for grain selection, which has been separately developed, the number of grain decreases linearly in a first stage of solidification. Therefore, the solidified structure should be observed at least two cross sections. Extrapolating the data to the chill surface, the grain density on the surface can be evaluated.

Validity of the proposed method has been checked using Al-10mass\%Cu alloy. A solidified shell, which was produced by dipping a chill plate in a molten alloy, has been closely observed. A grain is defined as a group of the dendrites that have the same orientation. Densities of grains were measured at two cross sections. Extrapolating these data to the surface, the grain density on the surface has been estimated. This estimated value agrees well with the density of grains, which was directly measured on the surface of the solidified shell.
\end{abstract}

KEY WORDS: nucleation; grain density; dendrite; grain; grain selection.

\section{Introduction}

It is well known that Hall-Petch's Relation ${ }^{1)}$ correlates the grain diameter with the yield stress of the metallic materials at ordinary temperatures. This relationship shows that a material with finer grains is much higher in yield stress than that with coarser grains. Following this, the mechanical properties except creep strength at high temperatures would be improved with finer grains. Thus, the refinement of solidified structure may be effective for improving the internal and surface qualities of the ingot. For example, the internal cracks in continuously-cast slabs have been actually overcome with fine equiaxed grains instead of coarse columnar grains. ${ }^{2}$ It is supposed that the surface defects such as longitudinal cracks in continuously-cast slabs would decrease with reducing the grain size at the surface of the slabs. There have been few reports that relate surface soundness of as-cast slabs and the grain size near the surface. Ohtani et al. have reported that an incidence of longitudinal cracks on the continuously-cast slabs of hypo-peritectic steels decreased when the electromagnetic stirring (EMS) in the mold is applied. ${ }^{3)}$ At the same time, they have observed the solidified structure near the surface and found that the solidified grain sizes decreased when the EMS in the mold was applied. Their observation may support the above-mentioned hypothesis.

Biloni and Chalmers have observed discs on the surface of an ingot of $\mathrm{Al}-\mathrm{Cu}$ and $\mathrm{Sn}-\mathrm{Pb}$ alloys as starting points of solidification. ${ }^{4)}$ They have also measured the solute content of the disc and concluded that the molten metal was under- cooled to the solidus temperature on the chill surface prior to the nucleation. Nishi et al. also have studied on the formation of discs ${ }^{5)}$ changing the roughness of the chill plates. They have concluded that the discs are the traces of nuclei and that this point locally touched well to the chill plate. Discs are the starting points of solidification and thus, the number of discs per unit area corresponds to the nucleation density on the chill surface. Following the studies of Biloni and Chalmers and Nishi et al., the dendrites grow from the discs via predendrites. Here, the crystallographic orientations of dendrites that grow from a disc are the same. Therefore, the group of dendrites, which have the same crystallographic orientation, indicates that these dendrites grow from one nucleus. In this study, the group of dendrites, which have the same crystallographic orientation, is defined as a grain. If a disc effectively forms a grain, the number of discs coincides with the number of grains. However, sometimes there are some discs in a grain as shown by Biloni and Chalmers. Therefore, the number of the effective nucleus, which grows in a grain, is expected to be smaller than the number of discs.

Hence, the size of grains on the surface of the ingot should be characterized. This may be carried out by observation of the solidified structure. It is uncertain to count directly the number of grains on the longitudinal cross section to the growth direction of solid phase. Two cases lead to uncertainty. Firstly, it is impossible to distinguish the grains that grow along the same direction but have the different crystallographic orientation due to rotation. Secondly, it is hard to judge a grain boundary when den- 
drites radially grow from a nucleus. On the other hand, it may be certain to count the number of solidified grains when the observation is made on the horizontal cross section to the growth direction of solid phase.

Recently, EBSP (Electron Backscatter Diffraction Pattern) method has been applied to the crystallographic orientation analysis. ${ }^{6)}$ However, it requires a special device on the scanning electron microscope. Furthermore, it is not desirable for the analysis of many ferrous alloys, since the crystallographic orientation when they solidify would change because of transformation.

With the aid of the engineering model for grain selection, the estimation for grain density on the chill surface will be proposed in this study.

\section{Model}

\subsection{Background and Model}

Based on the theory of columnar dendrite growth, a twodimensional engineering model for grain selection has been developed. The detail of the engineering model has been explained elsewhere. ${ }^{7,8)}$ Here, an outline of the model will be shown.

Each crystal has a preferred growth direction based on the anisotropy of surface tension. Popular metallic alloys such as ferrous alloys and aluminum alloys etc. have a cubic lattice and a preferred growth direction of $\langle 001\rangle$. From chill zone to columnar zone, the grain selection plays an important role. ${ }^{7-10)}$ Here, the grain, the growth direction of which is approximately the direction of heat flow, grows over other grains.

A simplified flow of the engineering model is shown in Fig. 1. The domain of calculation is shown in Fig. 2. The width and length are $D$ and infinity, respectively. When molten metal is poured into a mold, many grains randomly nucleate on the chill plate. The diameter and growth direction of the grain are given randomly as the initial condition. Since the scattering of the calculated results decreases with increasing the initial number of grains $\left(n_{0}\right),{ }^{7)} n_{0}$ used in this study is 200 . Comparing the growth directions of the neighboring grains, the direction of the grain boundary can be determined. A grain disappears when the grain boundaries intersect each other. Every time a grain disappears, the growth directions of neighboring grains are checked again and the directions of the grain boundary are determined. This procedure occurs repeatedly as solidification proceeds.

This model cannot estimate the actual value of grain size and growth length, though the similarity is kept constant during calculation. Therefore, the grain size and growth length normalized by any characteristic length can be compared each other. Here, an average initial diameter of the grain $\left(d_{0 \text { av }}\right)$ is used for a characteristic length, in order to compare with the experimental results.

\subsection{Validity of the Model}

Unidirectional solidification experiments have been carried out using as-received succinonitrile. ${ }^{11)}$ The change in the number of grains with growth length was measured when the solid/liquid interfacial morphology was dendritic. The number of grains was normalized by the initial number of grains, 16 and the growth length was normalized by the

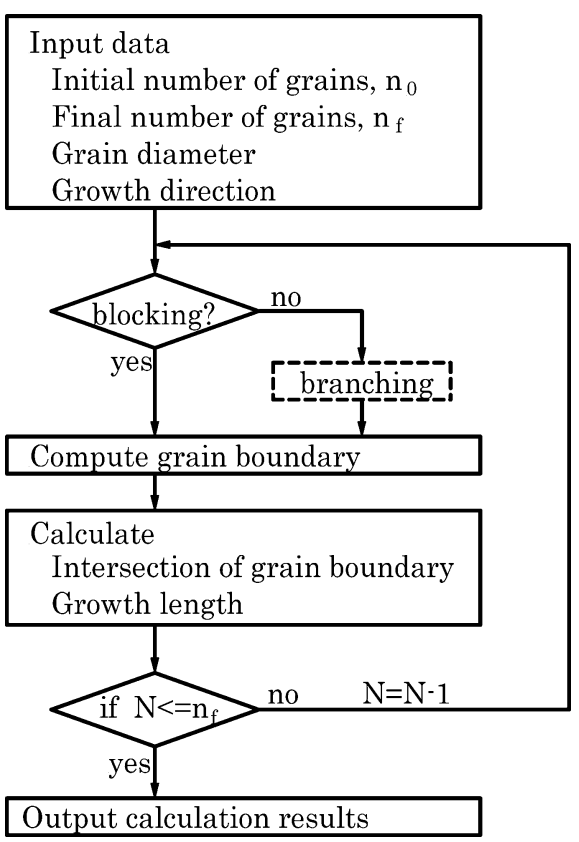

Fig. 1. A simplified flow chart of the engineering model for grain selection.

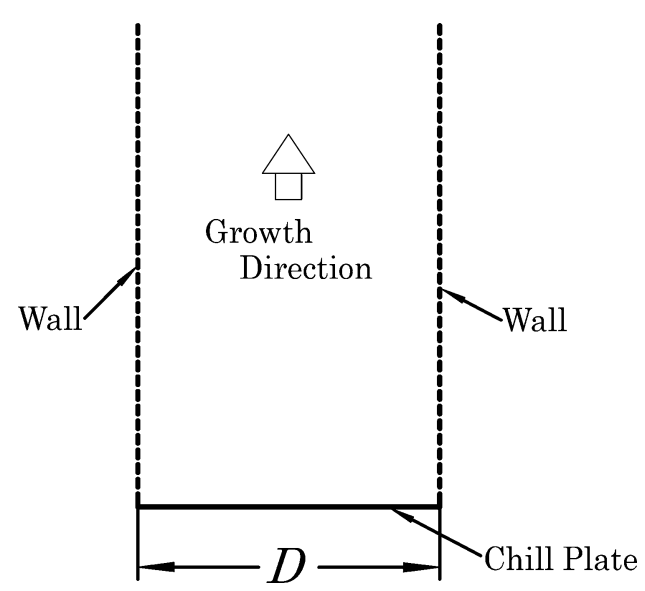

Fig. 2. A schematic drawing of the calculated domain.

average initial diameter of the grain. Figure 3 shows the comparison between the result of engineering model and the experimental result. There is little difference between the experimental and simulation results. The normalized number of grains decreases rapidly in the first stage of solidification and gradually in the latter half of solidification. This model can also predict this phenomenon.

\subsection{Evaluation for $n_{0}$ by the Model}

Another calculated result is shown in Fig. 4 with thick solid line. The number of grains $(n)$ and the growth length $(L)$ are normalized by $n_{0}$ and $d_{0 \mathrm{av}}$, respectively.

At the first stage of solidification, the number of grains decreases linearly as shown with the dotted line in Fig. 4. Assuming the dotted line has a slope of $k$, the equation of this line can be written as follows.

$$
\frac{n}{n_{0}}=1-k \frac{L}{d_{0 \mathrm{av}}}
$$

When the numbers of grains at two different distances from 


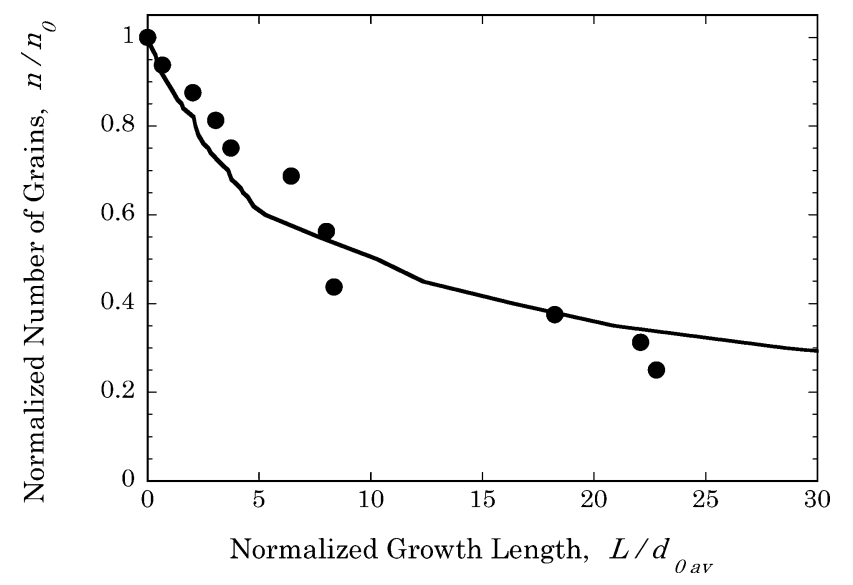

Fig. 3. Change in the number of grains with growth length. Calculated results agree well with the experimental results, which were carried out with as-received succinonitrile.

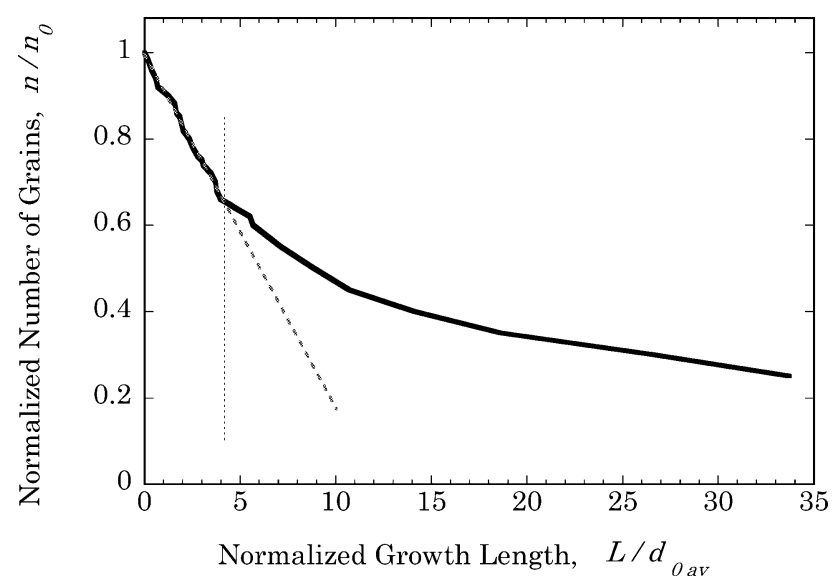

Fig. 4. Calculated results for the relation between number of grains and growth length. A dotted line indicates that the number of grains decreases linearly at the first stage of solidification

the surface are obtained, the initial number of grains at the surface can be estimated by extrapolating the measured data, since the dotted line shown in Fig. 4 is linear. When the two pairs of data are $\left(L_{1}, n_{1}\right)$ and $\left(L_{2}, n_{2}\right), n_{0}$ is obtained as follows, where $L_{1}<L_{2}$ and $n_{1}>n_{2}$.

$$
n_{0}=\frac{n_{1} L_{2}-n_{2} L_{1}}{L_{2}-L_{1}}
$$

This evaluation is valid as far as the thick curve in Fig. 4 can be assumed straight. It is clear from Fig. 4 that Eq. (2) is available when $L / d_{0 \text { av }}$ satisfies a following condition.

$$
\frac{L}{d_{0 \mathrm{av}}} \leq 4
$$

This indicates that the distance between the sections and the surface should be within 4 times of average initial grain size, in order to estimate the number of grains at the surface. This should be checked after observation, since the average initial grain size is unknown at the beginning.

Starting from the engineering model for grain selection, $n$ is originally the number of grains in a given width. Other

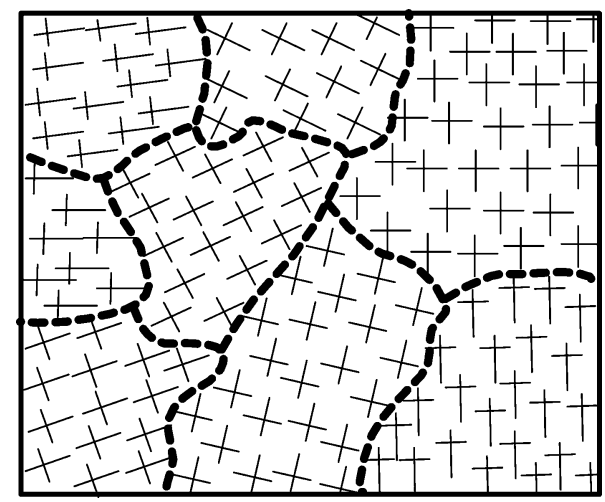

Fig. 5. A schematic illustration of solidified structure on the horizontal cross section. A grain is defined as a group of dendrites that grow in the same direction. Dotted lines indicate grain boundaries.

formulations for the number of grains, such as a number of grains per unit length $\left(\mathrm{mm}^{-1}\right)$ or a number of grains per unit area $\left(\mathrm{mm}^{-2}\right)$ are also applicable to Eq. (2).

\section{Experimental Procedure}

Aluminum-10mass $\% \mathrm{Cu}$ alloy was prepared from aluminum (purity: 99.99 mass\%) and copper (purity: 99.99 mass $\%$ ) and was melted at $800^{\circ} \mathrm{C}$ in the electric furnace under Ar atmosphere. Then the temperature of the furnace changed to $650^{\circ} \mathrm{C}$. After keeping over $1800 \mathrm{~s}$ at $650^{\circ} \mathrm{C}$, a chill plate $(18 \mathrm{~mm} \times 65 \mathrm{~mm} \times 4 \mathrm{~mm})$ was dipped in the molten alloy approximately $40 \mathrm{~mm}$ and pulled up. The chill plate was made from plain carbon steel and was ground by a 30-grit $\mathrm{SiC}$ grindstone. Molten aluminum-copper alloy then solidified on the chill plate. The solidified shell was removed from the chill plate and cut approximately $5 \mathrm{~mm} \times 5 \mathrm{~mm}$ for observation.

The surface of the specimen that faces to the chill plate was then observed directly by a FE-SEM. Backscatter electron images were used for observation. After this, the specimen was molded in the polyester resin for polishing. After polishing approximately $500 \mu \mathrm{m}$, the amount of polished thickness was measured by a micrometer. The specimen was then mirror-polished by $0.3 \mu \mathrm{m}$ alumina slurry. After coating with platinum, the specimen was again observed by the FE-SEM. This procedure occurred twice. Using the photographs of the FE-SEM, the grain structure was analyzed. The number of grains per unit area was then calculated at each distance from the surface.

It is the horizontal cross section to the growth direction of solid phase that the observation was made in this study. A schematic illustration of solidified structure observed in this cross section is shown in Fig. 5. As mentioned previously, the preferred growth direction of aluminum is $\langle 001\rangle$ and primary and secondary dendrite arms grow $\langle 001\rangle$, as far as dendritic growth condition is concerned. Therefore, it can be judged the group of dendrites that has the same crystallographic orientation by the directions of secondary arms and the patterns of arms. This group of dendrites is defined as a grain. The grain structure is also shown in Fig. 5 by the dotted lines.

The number of grains is counted with a following 


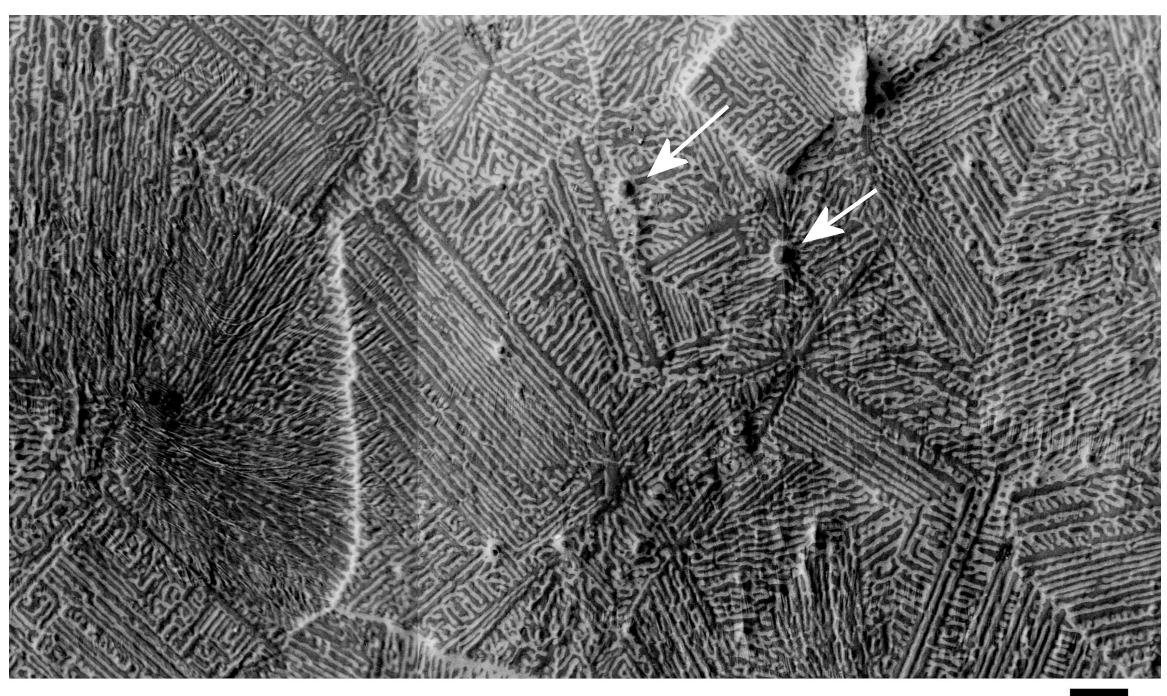

$100 \mu \mathrm{m}$

Fig. 6. BSE image at the surface of a solidified shell in $\mathrm{Al}-10 \mathrm{mass} \% \mathrm{Cu}$ alloy. Arrows indicate discs.

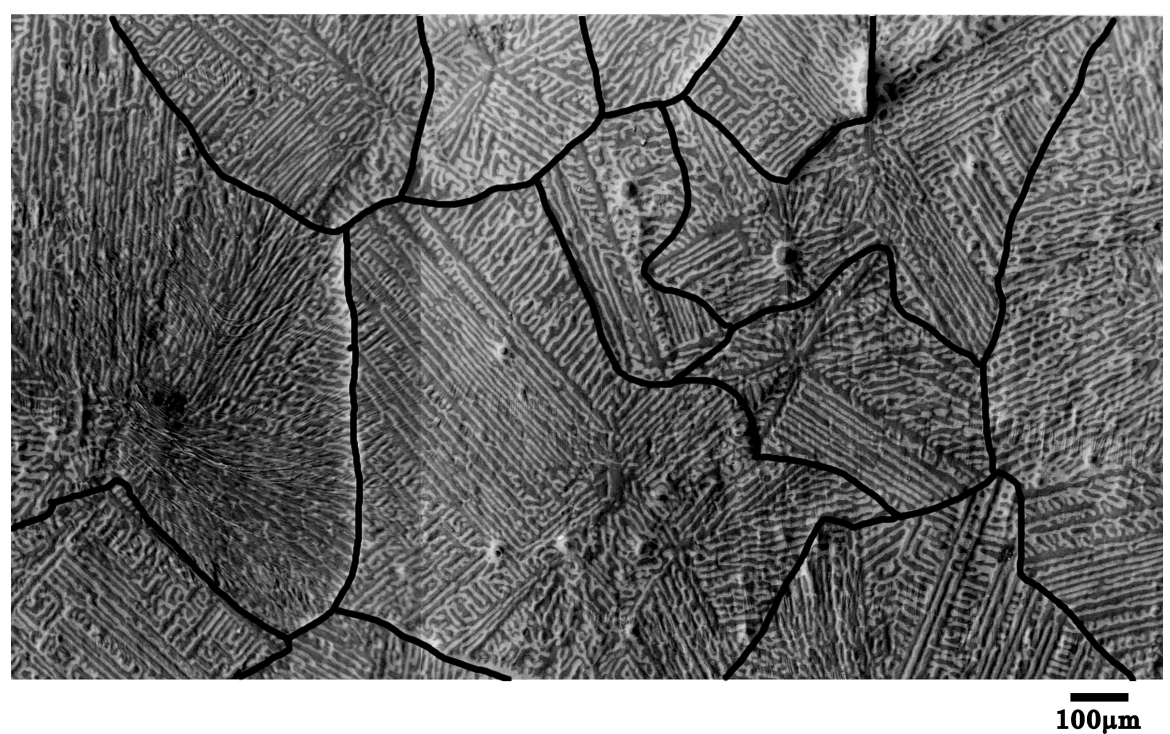

Fig. 7. Grain structure at the surface of a solidified shell.

method. When a grain is completely included in the area considered, the number of that grain is 1.0. On the other hand, when a grain is partially included in the area, the number of the grain is 0.5 , independent of the fraction.

\section{Experimental Results and Discussions}

\subsection{Observation of Solidified Structure on the Surface}

Figure 6 shows the BSE image of solidified structure on the surface. Because the atomic number of copper is larger than that of aluminum, copper segregated area is brighter than the other area. In the alloy system used in this study, copper is redistributed in the interdendritic region. Thus, the interdendritic regions are bright and the dendrite trunks and arms are dark.

The grain structure on the surface is judged from the following two bases as well as the standards described in Sec. 3. The dendrite arms that seem to grow radially from a disc are classified in a grain. Together with this, the dendrite arms that are perpendicular to each other are classified in one grain, even if the dendrite arms seem to be disconnected from one arm. Thus, it is possible to distinguish one solidified grain from others. The grain structure of Fig. 6 is shown in Fig. 7, where the grain structure is superimposed on the BSE image. There are 7.5 grains in this area shown in Fig. 7.

In Fig. 6, the arrows indicate discs on the surface of the solidified shell. It is found that a disc is not always observed in a grain. This points out that a disc is a starting point of solidification, however, there may be a starting point that does not show a disc. This may depend upon the undercooling for nucleation. Undercooling for nucleation $(\Delta T)$ has not been measured in this study, though it seems that $\Delta T$ is not so large that a nucleus exhibits a disc.

\subsection{Observation of Solidified Structure in the Speci- men}

The BSE image at a polishing thickness of $506 \mu \mathrm{m}$ is shown in Fig. 8. Some small perturbations are visible on the primary trunks and these indicate the preferred growth 


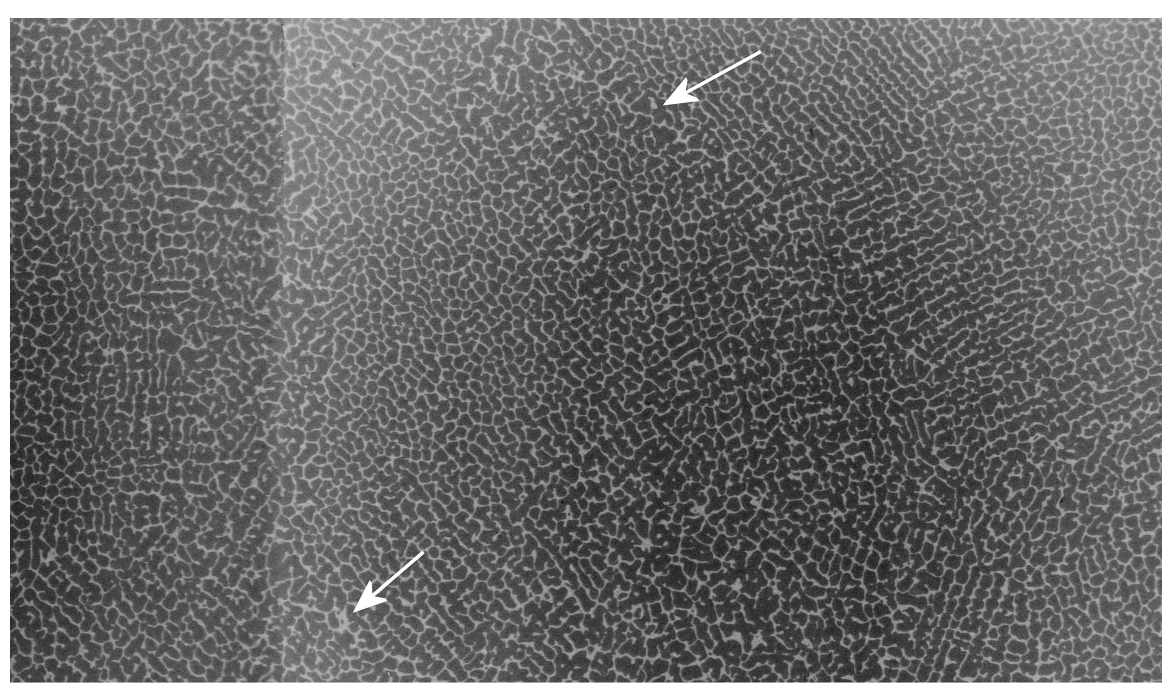

$\overline{100 \mu \mathrm{m}}$

Fig. 8. BSE image at a polishing thickness of $506 \mu \mathrm{m}$ in $\mathrm{Al}-10 \mathrm{mass} \% \mathrm{Cu}$ alloy. Arrows indicate copper segregated lines.

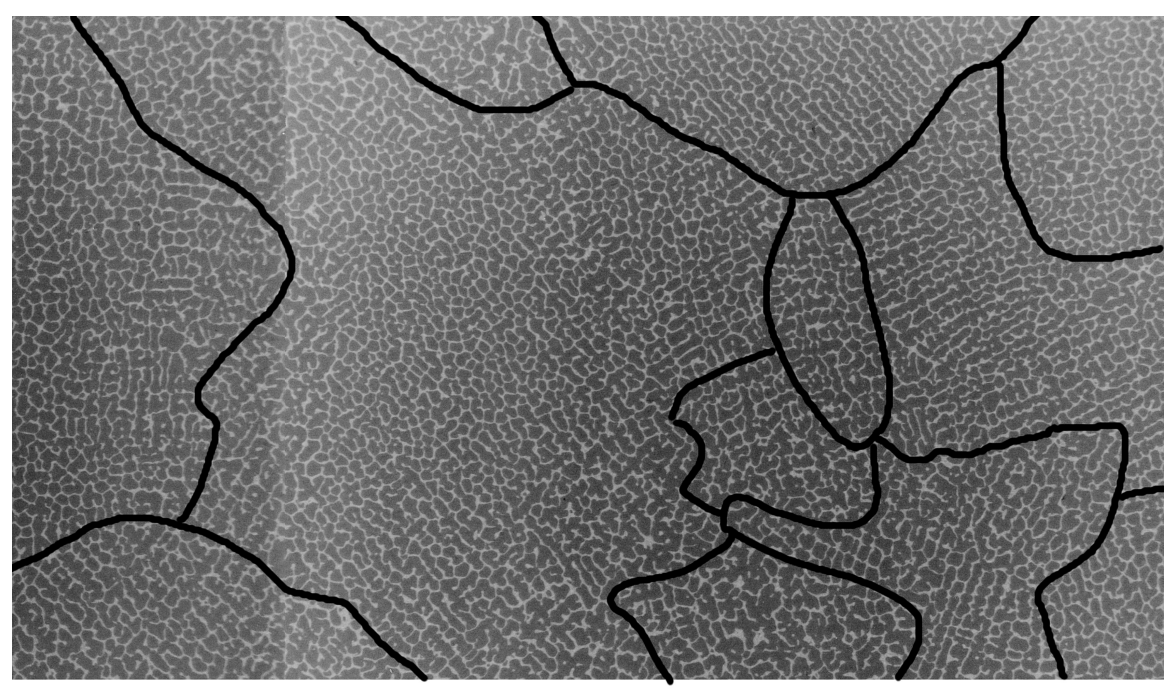

$1 \overline{100 \mu \mathrm{m}}$

Fig. 9. Grain structure at a polishing thickness of $506 \mu \mathrm{m}$.

direction. Therefore, it is possible to characterize the crystallographic orientation of the dendrite trunks. Based on the definition of grains as shown in Fig. 5, the grain structure superimposed on the BSE image is shown in Fig. 9. Here, there are 7.0 grains in this region.

Other remarkable features of the solidified structure shown in Fig. 8 are that there are some thick white lines. The arrows indicate these lines. They are the highly segregated region of copper and are found to coincide with the grain boundaries. Since the width of the segregated line is wider than the normal interdendritic region, the liquid film may remain along this line at a lower temperature, which is below the solidus temperature of the alloy. Thus, this may cause high temperature embrittlement because of a liquid film.

The BSE image at a polishing thickness of $1118 \mu \mathrm{m}$ is shown in Fig. 10. Since the temperature gradient and growth velocity are decreasing with growth, well-developed secondary arms are observed. ${ }^{12)}$ Thus, crystallographic ori- entation is easily recognized and grain structure can be judged. The grain structure superimposed on the BSE image is shown in Fig. 11. This is the same area as shown in Fig. 9. Here are 4.5 grains in this region. It is found that the number of grains at $1118 \mu \mathrm{m}$ is smaller than that at $506 \mu \mathrm{m}$ because of the grain selection.

\subsection{Evaluation of Grain Density at the Surface of the Chill Plate}

Numbers of grains are measured in the observed areas that are between $12 \mathrm{~mm}^{2}$ and $13 \mathrm{~mm}^{2}$. Then the densities of grains at two sections are calculated. The relation between the distance from the chill surface and the density of grains is shown in Fig. 12 with solid circle. The density of grains decreases with increasing the distance from the chill surface.

Based on the result of the engineering model, it is possible to estimate the number of grains on the surface. The solid line in Fig. 12 is the straight line connecting two ex- 


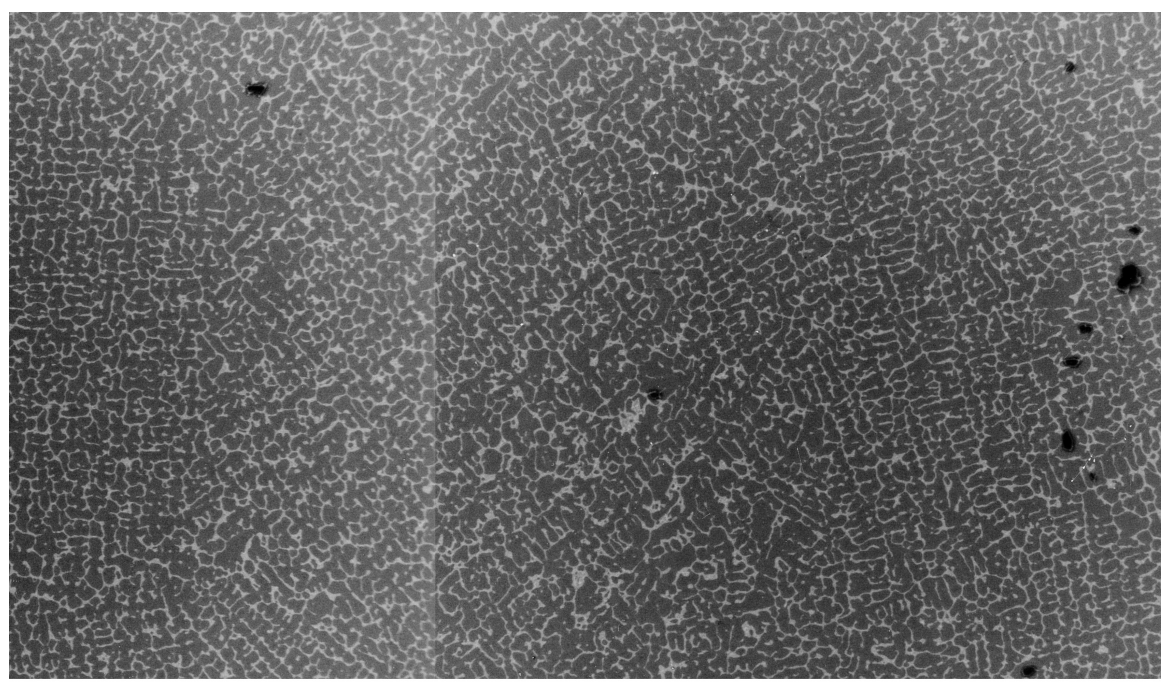

$\overline{100 \mu \mathrm{m}}$

Fig. 10. BSE image at a polishing thickness of $1118 \mu \mathrm{m}$ in $\mathrm{Al}-10 \mathrm{mass} \% \mathrm{Cu}$ alloy.

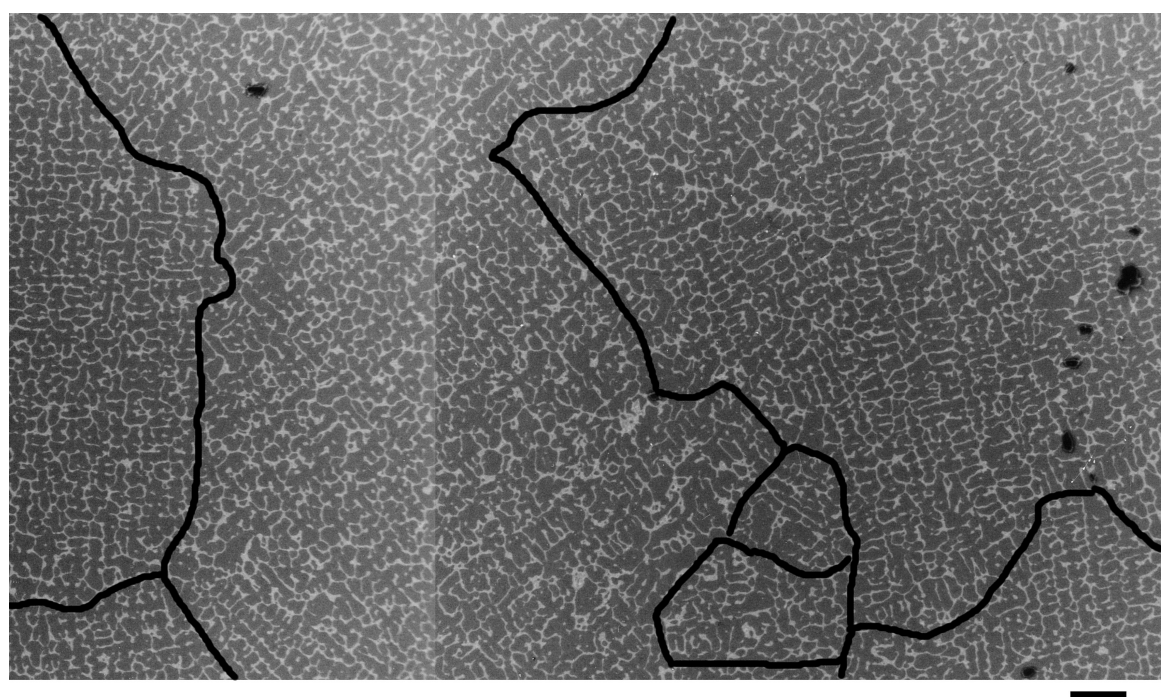

$\overline{100 \mu \mathrm{m}}$

Fig. 11. Grain structure at a polishing thickness of $1118 \mu \mathrm{m}$.

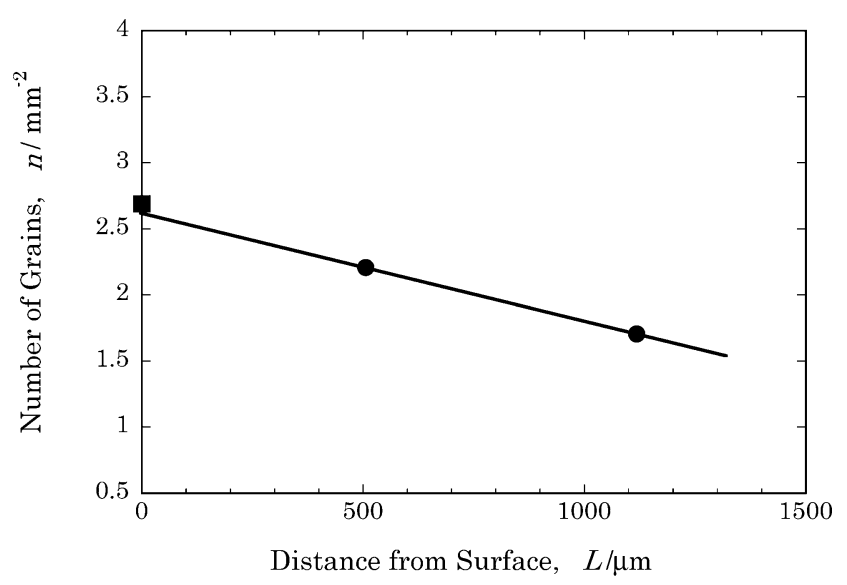

Fig. 12. Relationship between the length from the surface and the number of grains per unit area. The straight line indicates the extrapolation to the surface to evaluate the grain density. Solid square shows the directly measured density of grains on the surface of the solidified shell. perimental data. Extrapolating to $L=0$, the number of grains on the surface can be obtained graphically. This value is found to be $2.60 / \mathrm{mm}^{2}$. This is also calculated using Eq. (2) and naturally agrees with this estimation.

From the BSE image of the surface of the solidified shell as shown in Figs. 6 and 7, density of grains can be directly obtained. Here again, the total area for measurement was approximately $12 \mathrm{~mm}^{2}$. This value is $2.69 / \mathrm{mm}^{2}$ and is also shown in Fig. 12 with solid square. This agrees quite well with the estimated value, $2.60 / \mathrm{mm}^{2}$.

The average initial diameter of the grain $\left(d_{0 \mathrm{av}}\right)$ can be calculated, assuming a grain is circle. When the density of grains is $2.69 / \mathrm{mm}^{2}$, then $d_{0 \mathrm{av}}$ is $688 \mu \mathrm{m}$. The distances between the cross sections and the surface are $506 \mu \mathrm{m}$ and $1118 \mu \mathrm{m}$ respectively, and they are within the limit of applicability as indicated in Eq. (3). Therefore, it can be concluded that the evaluation of the grain density on the chill surface is valid.

In this study, $\mathrm{Al}-10 \mathrm{mass} \% \mathrm{Cu}$ alloy has been chosen. One of the major reasons of this choice is that it is possible to 
observe the solidified structure on the surface without treatment. In almost all ferrous alloys, on the other hand, the solidified structure on the surface cannot be observed without treatment. In such cases, the present method is effective for evaluation of grain density on the surface.

\section{Conclusions}

Grain density on the surface, which is important for the surface quality of the cast-products, has been evaluated in this study theoretically and experimentally. The following conclusions have been derived.

(1) Observation at least two cross-sections should be made, in order to evaluate the grain density on the chill surface.

(2) The distance between the cross sections to be observed and the surface should be less than 4 times of average initial diameter of grain.

(3) A disc is not always observed, depending upon the undercooling for nucleation.

(4) The grains can be identified by the growth direction of secondary dendrite arms on the horizontal cross section.

(5) Grain density on the surface obtained at two cross sections by extrapolating to the chill surface agrees well with the directly measured value.

\section{REFERENCES}

1) N. J. Petch: Philos. Mag., 3 (1958), 1089

2) H. Takeuchi, Y. Ikehara, T. Yanai and S Matsumura: Tetsu-toHagané, 63 (1977), 1287.

3) Y. Ohtani, J. Fukuda, J. Nakashima, H. Esaka and K. Sato: $C A M P$ ISIJ, 9 (1996), 764.

4) H. Biloni and B. Chalmers: Trans. Metall. Soc. AIME, 233 (1965), 373.

5) N. Nishi, H. Takeuchi and S. Uchida: Imono, 54 (1982), 718.

6) H. Takatani, Ch.-A. Gandin and M. Rappaz: Acta Mater., 48 (2000), 675.

7) H. Esaka, K. Fujita, H. Daimon, M. Tamura and K. Shinozuka: J. Jpn. Inst. Met., 64 (2000), 1206.

8) H. Esaka, M. Tamura and K. Shinozuka: Mater. Trans., 44 (2003), 829.

9) H. Esaka, W. Kurz and R. Trivedi: Solidification Processing 1987, The Institute of Metals, London, (1988), 168.

10) D. Walton and B. Chalmers: Trans. Metall. Soc. AIME, 215 (1959), 447.

11) H. Esaka, M. Tamura and K. Fujita: Proc. of Modeling of Casting and Solidification Process IV, Hanrimwon, Seoul, (2000), 133.

12) W. Kurz and D. J. Fisher: Acta Metall., 29 (1981), 11. 